\title{
THE PRACTICAL APPLICATION OF MEMORY RESEARCH: WHY WE CAN DO BETTER
}

\author{
Michael M. GRUNEBERG ${ }^{1)}$ and Douglas J. HERRMANN ${ }^{2)}$ \\ ${ }^{1)}$ Swansea University, U.K. and ${ }^{2)}$ Indiana State University, U.S.A.
}

\begin{abstract}
This paper looks at the background to the recent development of present day applied memory research and considers its present day successes and failures. Applied memory research emerged into the view of science in general in that late 1970s. Its reception was controversial at best. Many basic researchers seemed to feel that they should direct the course of not only basic research but also applied research as well. Gradually it became apparent that while the missions of basic and applied research were similar in relying on the scientific method, these two different branches of science address different phenomena in different contexts. However, applied memory research is still slowed unfairly. Problems which impede the progress of applied memory research, including difficulties of evaluation, lack of peer esteem, and unrealistic expectations of journal reviewers of research conducted under ecologically valid conditions, are discussed. Nevertheless, applied memory research is coping with the challenges put to it, and perhaps because of the scepticism it faces, is accelerating its contribution to the needs of the world.
\end{abstract}

Key words: applied memory, future directions

Although an interest in the nature of memory was present at the foundation of modern psychology, (Ebbinghaus, 1887), it is probably fair to say that it was in the 1960's that psychologists returned in force to examine the nature of memory in considerable detail. One of the stimulants to further research was the question of whether the evidence supported a distinction between short and long term memory (Melton, 1963; Baddeley, 1966) and this debate continues to the present day in the form of question of the nature and existence of a working memory separate from long term memory. In order to answer the question, a number of other questions required answers, such as the nature of the limitation of our ability to store memory information (Gruneberg, 1969), the nature of the serial position curve, the nature of the cause of short and long term coding and the nature of forgetting (Gruneberg, 1970).

While all this activity was going on, little attempt was made to address the practical implications of the many new findings which were emerging from basic research, although it was certainly the case that researchers such as Loftus and her colleagues(e.g. Loftus \& Palmer, 1974) were publishing seminal work on the nature of eyewitness testimony at this time.

Because there was felt to be a neglect of the practical implications of memory

Correspondence concerning this article should be addressed to Michael M. Gruneberg, Department of Psychology, Swansea University, Singleton Park, Swansea SA2 8PP, U.K. (e-mail: M.M.Gruneberg@) Swansea.ac.uk), or Douglas J. Herrmann, Department of Psychology, Indiana State University, Terre Haute, U.S.A. (e-mail: pyhermn@root.indstate.edu). 
research, the First International Conference on Practical Aspects of Memory was held in Wales in 1978. It was arguably a turning point in applied memory research, since over 90 papers, many by well established basic researchers were presented at that meeting, showing beyond doubt that many psychologists felt the desirability of making memory research responsive to the needs of society as well as, and not instead of, the need to further our understanding of the nature of memory.

Probably the most significant paper presented at the conference was that of Neisser (1978). Neisser argued that the work of memory researchers was not being directed at important issues. In a now famous phrase he argued "If $\mathrm{X}$ is interesting or socially significant aspect of memory, then psychologists had hardly ever studied X". In fact, Neisser admitted at the end of the conference he was wrong, in that a large number of psychologists had shown at the conference a willingness to investigate such practical questions as the nature of autobiographical memory, prospective memory, memory in education, memory improvement, as well as the more established areas of eyewitness memory and developmental aspects of memory.

In fact, Neisser's paper was probably much more important for the questions he raised about methodology in memory research than for his criticism of lack of interest in practical application. He regarded the paradigms used in the laboratory as basically arid, focussed on answering questions of very limited interest. In order to answer questions of greater importance, investigations had to be ecologically valid, which in many cases required moving from the laboratory to the greater uncertainty of the outside world.

The problem with ecological validity, as far as many basic researchers are concerned, is that leaving the safety of the laboratory means losing the rigorous control afforded by the laboratory. Banaji and Crowder (1989) argued that lack of laboratory control meant that findings could not be generalised beyond the particular set of situations actually under investigation. The underlying threat is that without rigorous experimental control, the science of psychology itself is threatened.

\section{The Problem of Generalising From the Laboratory}

It is perhaps surprising that basic researchers set such store on the need to be able to generalise, since experiments in psychology laboratories are often conducted in such a way as to preclude generalising from particular sets of experiments. Leaving aside the not inconsiderable problem that much psychology is established on populations of intelligent young adults (students), that when a phenomenon is new, these factors which can vary are often unknown, and not necessarily random, and that it is almost impossible to predict from any one carefully controlled experiment what interactions with other important variables may produce. Studying the properties of sodium and chlorine, after all, hardly lead to predictions about the properties of common salt. From the perspective of applied memory research, it is unlikely that, for example, studies of stress and memory in the laboratory will lead to safe predictions of the effects of high levels of stress on real life eyewitness memory in any way that is universally generalisable. Finally, as far as 
memory research is concerned, it is clear that findings based on one experimental paradigm do not generalise consistently across other paradigms (Herrmann, Raybeck, \& Gruneberg, 1998; Gruneberg \& Morris, 1992). Memory is a composite of different skills and it is simply naive to generalise from laboratory findings to interactions in the real world. (See Herrmann \& Gruneberg (1993), Gruneberg and Herrmann (1998) for extended reviews of the problems of generalisation from the laboratory to real life research).

Apart from these problems, ethical considerations mean that if application is to advance, some investigations must take place in situ. It would be totally unethical for example to carry out investigations on eyewitnessing and stress which aimed to mimic the real life stress of a real rape or murder. Yet a number of investigations have shown that memory in such real life situations is often much better than would be expected from laboratory studies (e.g. Johnson, 1993).

It is not being argued, of course, that real life application has not benefited enormously from laboratory research, or that no laboratory research can be generalised to real life situations. What is being argued is that for real life application to be effective, it must be tested under real life conditions, and this aspect of application is one that is often neglected by academic psychologists at least.

\section{SuCCESSES OF APPLied MeMory ResearCh}

As noted above, until the 1970's, relatively little attention had been paid by memory researchers to the importance of the practical application of research findings. Since the First Practical Aspects of Memory Conference, however, it is probably fair to say the situation has been transformed, even if it is still not as good as it could be. In the last twenty-five years, there has been a massive increase in our understanding of eyewitnessing, prospective memory, autobiographical memory, memory and aging, and educational implications of memory, and this list is by no means exhaustive (see Gruneberg \& Herrmann, 1998). While considerable progress has been made in all these areas, for reasons of space only one will be highlighted here, eye-witnessing. Eyewitnessing has been chosen because it has undoubtedly been one of the major successes of applied memory research.

\section{EYEWITNESS RESEARCH}

Although, as noted earlier, eyewitness research is long established in psychology (e.g. Münsterberg, 1908), it is undoubtedly the case that great impetus to eye-witnessing research came with the work of Loftus and her colleagues in the 1970's. In a series of experiments, it was demonstrated just how easy it was to induce mistakes in the recall of experimental subjects by presenting questions designed to mislead (Loftus \& Palmer, 1974 ) and in providing false past event information (Loftus \& Burns, 1982). Since then, 
a large number of studies have shown how, under some circumstances, eyewitness evidence can be unreliable.

A particular area where eyewitness memory has been demonstrated to be unreliable is in eyewitness identification. Not only has the reliability of identification been shown to be unreliable, particularly in the case of poor viewing conditions, but even more worrying, a large number of studies have shown that for eyewitness identification at least, there appears to be little or no relationship between how confident a witness is and how accurate. Since a number of studies have shown that jurors rely heavily on the confidence of eyewitnesses, clearly such a finding is both worrying and of considerable practical importance. As Gruneberg and Sykes (1993) have pointed out, however, it is dubious if findings based on laboratory studies of face identification can be generalised to real life situations involving say, accounts of what individuals said, what suspects were wearing, and so on, without considerable qualification. Nevertheless the clear evidence of witness unreliability under some conditions, and the questionable relationship between confidence and accuracy in some situations is of considerable practical significance.

Other areas where eyewitness research has proved of considerable value is in line-up identification and in interviewing techniques for witnesses. Studies reported by Wells, Seelau, Rydell, and Luus (1994), for example, have shown that successive presentation of criminal 'suspects' in a line-up identification leads to fewer false positive identifications than does simultaneous presentation of suspects. Furthermore, research on how to reduce anxiety in witnesses has led to the widespread adoption of one-way screens in police units Specialist units in the U.K. now adopt procedures such as ensuring that the investigating officer and the officer in charge of the line up parade are not the same person, and great care is taken in such units in matching fairly, the suspect and foils in line-up parades (see, e.g. Gruneberg, 1998).

As far as interviewing procedures are concerned, one of the major successes of applied memory research has been the widespread implementation of the cognitive interview, first developed by Geiselman and Fischer (see e.g. Geiselman \& Fisher, 1997, for a review). which has consistently shown that by applying a number of strategies proven in laboratory situations recall by interviewees is considerably enhanced. For example, the cognitive interview requires interviewees to tell all they know, however trivial they think it might be, to imagine themselves back in the situation, seeing the incident from the perspective of others, recalling in reverse order, and so on. Results of the cognitive interview typically show recall improvements in the order of $40 \%$, with little increase in false memory recall (see e.g. Geiselman \& Fisher, 1997, for a review ).

\section{Some Areas of Under ACHIEVEMENT}

While there is little doubt that eyewitness research has been of considerable practical benefit, there are of course areas in eyewitnessing research where laboratory results are not clearly generalisable to the real world. In particular, as mentioned above, it is not ethical or practicable to conduct research which mimics accurately real life stress, which 
for example, is attendant on witnessing a real life rape or murder. There are some indications that real life recall gives higher levels of retention than would be expected from studies which take place in the laboratory (Johnson, 1993).

It is in precisely these situations where real-life phenomena are of interest that applied memory research is arguably at its weakest. Pressley (1996) for example describes the difficulty of carrying out research in classroom situations where the needs of teaching take precedence over the needs of research. Normal control groups are difficult to assign and children have the unfortunate habit of talking to each other about what is going on. Again in real life situations constituting control groups at all may be difficult in terms of adequate numbers or control of extraneous variables.

Another area presenting real difficulties is the study of memory failures. Herrmann and Gruneberg (1999) and Herrmann, Gruneberg, Fiore, Schooler, and Torres (2002), for example, employed a new approach to examining memory failures which involves individuals recalling incidents when they had memory failures and then recalling the reasons for these failures. This approach was chosen because of a dissatisfaction with the standard approach of using questionnaires which requires individuals to assess how frequently they had memory failures of a given type, such as forgetting names. Such an approach however, does not require the respondent to remember a single memory failure and it is anything but clear what the nature of the process of recalling the frequency of memory failures is. On the other hand, an approach based on recall of particular memory failures could suffer from inaccurate memory for the memory failure, and is sometimes dismissed by critics for this reason. This is, to say the least, unfortunate since this approach is similar to investigations on other aspects of autobiographical memory, where recall of major aspects of important events have been shown to be largely accurate (Wagenaar \& Groenweg, 1990). Of course there is always the possibility that some recalls of memory failures may be inaccurate, but given the effectiveness of standard approaches, it seems to the present authors that understanding of the mechanisms of memory failure is more likely to be achieved by examining the recall of real failures in everyday life, than in refusing to use such an approach because of the possibility of some small percentage of recalls being inaccurate.

Thus, one of the problems of practical application of memory research is the unwillingness of many basic researchers to allow a certain degree of ambiguity in investigations. Applications are almost inevitably going to be used in situations not envisioned by the person who designs the application. Therefore ambiguity in research design helps to develop fuller explanations of the phenomena and to identify some ways that an application may be used beyond what was originally intended. As Gruneberg, Morris, Sykes, and Herrmann (1996) have pointed out, other approaches to psychology such as organisational psychology, are willing to allow the publication of studies where control groups are inadequate or where results may be ambiguous, as in the area of job enrichment. Here the approach has been to allow publication of less than perfect studies, but to use meta-analysis to examine major trends. Clearly this approach has its dangers. However, the greater danger resulting from this approach may be in not attempting to identify manipulations of practical importance than in the possibility of making a mistake 
by possibly misidentifying a manipulation as being important. The result in Organisational psychology has been to enhance considerably the application of research to real life situations.

It is not just the attitude of basic researchers to real-life research which makes for difficulties in publishing the results of such research. In both the U.S.A. and the U.K., the academic reward system is strongly weighted against actual application. This is because as noted above, actual application is often perceived to less rigorous than laboratory based research, and therefore tends to be published in less prestigious journals. However, the lesser degree of rigor of applied research is an illusion. In actuality, real life application is more time consuming than laboratory based research. Where a fully balanced design can be easily used in the laboratory, extra effort is needed in applied research to control for the influence of extraneous variables that basic research obviates. With more time invested in a research project, applied research normally leads to fewer publications than basic research. Additionally, the success of application is far more difficult to measure than is basic academic research, where publications in high prestige journals are the touchstone of success in formal academic assessments, such as the Government Research Assessment Exercise carried out recently in the U.K.

In fact, in the U.K. in 2002, an attempt was made to assess the value of application of psychology in all psychology departments throughout the U.K. This was conducted through the University research assessment exercise (RAE). The RAE paid lip service to the value of applied research by having a panel of 'experts' make assessments of the value of application of research of each psychology department in the U.K. It was an interesting exercise, since no criteria of successful application was ever made available to U.K. researchers prior to such an assessment, so information on important criteria of success, such as the actual influence of an application, as opposed to papers published in journals on the application could not be assessed. Gruneberg et al. (1996) noted the complexity of assessing application, and the need to examine a large number of criterion of success for different kinds of application. So long as future attempts at assessment of the success of application are as crass as the recent attempt in the U.K., little if any progress in real life application will be envisaged which does not conform to the narrow and largely irrelevant criteria of academic paper publication.

In summary, the practical application of memory research has come a long way since the First Practical Aspects of Memory Conference in 1978. Two more Practical Aspects Conference have been held (1988 and 1994). A large amount of work of practical relevance has been published. A learned society, The Society for Applied Research Memory and Cognition - (SARMAC), has been successfully founded in 1994 which has held several international meetings since its founding. Also two journals have been established which are devoted solely to publishing applied cognitive research: Applied Cognitive Psychology; Cognitive Technology.

It would be fair to say that a number of areas such as eyewitnessing research, have made considerable progress, but progress has not been as great as it should have been in areas where real life research is required and where such real life research precludes structured approaches such as the use of matched control groups or precise measures of 
the phenomena under investigation. Furthermore, the emphasis, as evidenced by the Research Assessment Exercise in the U.K., on memory application success in terms of published research, rather than seeking from applied researchers a diversity of evidence on the success of applications, such as the number of schools adopting a particular procedure, long term assessment of interventions published in non psychology journals, as well as psychology journals, sales figures where appropriate, increases in attendance at clinics, reduction in training, number of lives saved, number of accidents reduced. In many cases such information is not published or not published in psychology journals, although we believe that someday this information will be published to assess the effectiveness of applied cognitive applications.

Dispite the limitations on progress described above, there is no doubt that an interest in practical application of memory research has come a long way since the first Practical Aspects of Memory conference in 1978. Applied research is now almost commonplace, publication of applicable research is increasingly common, and there is some official recognition of the value of application of psychology at a national level, even if the ability to assess its value leaves a lot to be desired. Our belief is that the next tweny five years will see as great an advance in the application of memory research as the last twenty five years have certainly shown.

\section{REFERENCES}

Baddeley, A. D. 1966. Short-term memory for word sequences as a function of acoustic, semantic and formal similarity. Quarterly Journal of Experimental Psychology, 18, 362-365.

Banaji, M. R., \& Crowder, R. J. 1989. The bancruptcy of everyday memory. American Psychologist, 44, $1185-1193$.

Ebbinghaus, H. E. 1887. Memory: A contribution to experimental psychology. New York: Dover.

Geiselman, R. E., \& Fisher, R. P. 1997. Ten Years of Cognitive interviewing. In D. G. Payne \& F. G. Conrad (Eds.), Intersections of basic and applied research (pp. 291-310). Mahwah, N.J.: Erlbaum.

Gruneberg, M. M. 1969. The limited capacity hypothesis and short term memory. Acta Psychologica, 31, 326-339.

Gruneberg, M. M. 1970. A dichotomous theory of memory: Unproved and unprovable. Acta Psychologica, 34, 489-496.

Gruneberg, M. M. 1998, July. Progress on parade. Police Review.

Gruneberg, M. M., \& Herrmann, D. J. 1998. Practical truths in memory. In S. Lynn \& K. McConkey (Eds.), Truth in memory (pp. 464-480). New York: The Guilford Press.

Gruneberg, M. M., \& Morris P. E. 1992. Applying memory research. In M. M. Gruneberg \& P. E. Morris (Eds.), Aspects of memory: The practical aspects. London: Routledge.

Gruneberg, M. M., Morris, P. E., Sykes, R. N., \& Herrmann D. J. 1996. The practical application of memory research: Problems in the relationship between theory and practice. In D.J. Herrmann, C. McAvoy, C. Hertzog, P. Hertel, \& M. Johnson (Eds.), Basic and applied memory research, Vol. 1 (pp. 63-82). Mahwah, N.J.: Erlbaum.

Gruneberg, M. M., \& Sykes, R. N. 1993. The generalisability of confidence-accuracy studies in eyewitness memory. Memory, 1, 185-190.

Herrmann, D. J., \& Gruneberg, M. M. 1993. The need to expand the horizons of the practical aspects of memory movement. Applied Cognitive Psychology, 7, 553-565.

Herrmann, D. J., \& Gruneberg, M. M. 1999. How to cure your memory failures. London: Orion.

Herrmann, D. J., Gruneberg, M. M., Fiore, S., Schooler, J., \& Torres, R. 2002, March. Accuracy of reports of memory failures and their causes. Paper presented at the 3rd International Conference on Memory, 
Tsukuba, Japan.

Herrmann, D. J., Raybeck, D., \& Gruneberg, M. M. 1998. A Clash of scientific cultures. Terre Haute: Indiana State University press.

Johnson, M. T. 1993. Memory phenomena in the law. Applied Cognitive Psychology, 7, 603-618.

Loftus, E. F., \& Burns, H. J. 1982. Mental shock can produce retrograde amnesia. Memory and Cognition, 10, 318-323.

Loftus, E. F., \& Palmer, J. C. 1974. Reconstruction of automobile destruction: An example of the interaction between memory and language. Journal of Verbal Learning and Verbal Behavior, 13, 585-589.

Melton, A. W. 1963. Implications of short term memory for a general theory of memory. Journal of Verbal Learning and Verbal Behavior, 2, 1-21.

Münsterberg, H. 1908. On the witness stand. New York: Doubleday.

Neisser, U. 1978. Memory: What are the imortant questions? In M. M. Gruneberg, P. E. Morris, \& R. N. Sykes (Eds.), Practical aspects of memory (pp. 3-14). London: Academic Press.

Pressley, M. 1996. Personal reflections on the study of practical memory in the mid 1990': The complete cognitive researcher. In D. J. Herrmann, C. McAvoy, C. Hertzog, P. Hertel, \& M. Johnson (Eds.), Basic and applied memory research, Vol. 2 (pp. 19-35). Mahwah, N.J.: Erlbaum.

Wagenaar, W. A., \& Groenweg, J. 1990. The memory of concentration camp survivors. Applied Cognitive Psychology, 4, 77-87.

Wells, G. L., Seelau, E. P., Rydell, S. M., \& Luus, C. A. 1994. Recommendations for properly conducted lineup identification tests. In D. F. Ross, J. D. Read, \& M. P. Toglia (Eds.), Adult eyewitness memory (pp. 223-244). New York: Cambridge University Press.

(Manuscript received August 12, 2002; Revision accepted September 30, 2002) 